\title{
Stability analysis of concrete block retaining wall based on a scaled laboratory
}

\author{
Deni Irda Mazni ${ }^{1,2^{*}}$, Abdul Hakam ${ }^{1}$, Jafril Tanjung ${ }^{1}$, and Febrin Anas Ismail ${ }^{1}$ \\ ${ }^{1}$ Andalas University, Civil Engineering Department, Padang, Indonesia \\ ${ }^{2}$ Dharma Andalas University, Program Study of Civil Engineering, Padang, Indonesia
}

\begin{abstract}
A concrete block retaining wall is supported by its weight. This block retaining wall structure has some advantages, including lower construction costs, a water-permeable construction that produces less water pressure behind the wall, and a more flexible construction because it can follow the ground's contours. Rankine's theory is usually used to design this block retaining wall. According to this theory, the failure pattern behind the wall forms an angle of $450+\bullet / 2$ with the horizontal plane. The laboratory tests indicate that the pattern of failure or the pattern of sand movement behind the wall is similar to the letter S. From the sandy soil of failure pattern curve, look for a functional equation approximating the pattern. The equation of the function obtained is an equation of the third-order function. An analysis of the sliding, overturning, and overall stability block retaining wall is based on this equation of the cube function. Analysis for overall stability using the method of slices, dividing the failure area by several slices. These function equation order three is needed to get the area and length failure.
\end{abstract}

\section{Introduction}

The purpose of retaining walls is to support the weight of sloped soil and buildings, earthquake loads, machine loads that produce vibrations, and others [1]. It is important to note that retaining walls can remain functional and stable based on the weight of the retaining wall itself and the weight of the soil above the heel of the wall.

The advantages of a concrete block retaining wall include its ease of construction; the footing is simply a gravel leveling pad, and the units are dry-stacked without the use of mortar, steel reinforcement, or grouting [2], [3]. The Concrete block retaining walls are often considered as rigid (conventional) retaining walls when designing shear and overturning stability [4-6].

The failure behavior or pattern of a block retaining wall and a gravity wall is not necessarily the same on the field. In laboratory experiments, the failure plane of sand behind the concrete block retaining wall is not a straight line, as predicted by Rankine's theory (a straight line), but is more like an S curve [7].

There have been several failures when designing retaining walls. Sharma (2011) reported on a study on the failure of retaining walls, which serves as a helpful lesson for future consideration of the stability of retaining walls [8]. The situation was discussed in detail in the report, including the retaining wall's failure mechanism. The failure of retaining walls is mainly caused by the incorrect design of retention and support systems based on experience [9-10].

As a result, a more thorough examination of this retaining wall is required, beginning with examining the failure pattern.

\section{Block Retaining Wall (Concrete)}

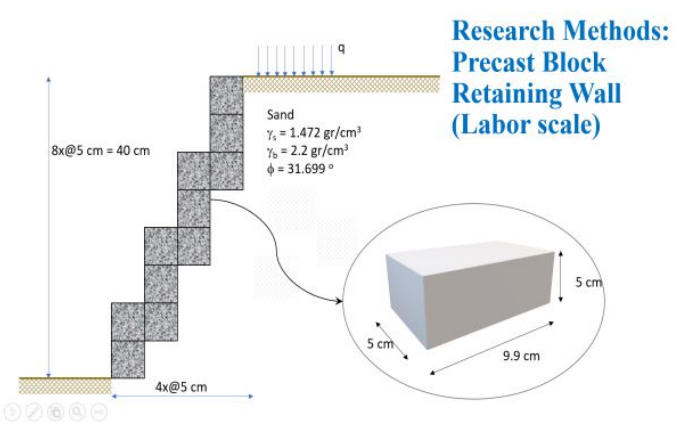

Fig. 2. Failure pattern due to static load (Rankine's theory)

In the laboratory, the model of the block retaining wall was made, as shown in Fig. 1. The block retaining wall is made of a mixture of cement, sand, and water with 9.9 (length) x $5 \mathrm{~cm}$ (width) x $5 \mathrm{~cm}$ (height). The blocks are

*Corresponding author: deniirdamazni@gmail.com 
arranged in a glass box with a diameter of $40 \mathrm{~cm}$ (length), $10 \mathrm{~cm}$ (width), $80 \mathrm{~cm}$ (height). The surface of the embankment behind the wall is level, with the soil type being sand. The total height of the wall is $40 \mathrm{~cm}$, and there are 11 blocks in total. There is no adhesive or connection between the concrete blocks.

In classic theory (Rankine's theory), to calculate the overall stability of the block (segmental) retaining wall, assuming the failure pattern behind the wall resembles a straight line forming an angle of $\left(45^{0}+\phi / 2\right)$ with the horizontal plane in Fig. 2. According to NCMA, the block retaining wall failure pattern is predicted to appear like a straight line in Fig. 3. even though the actual on the field is not always the same [11].

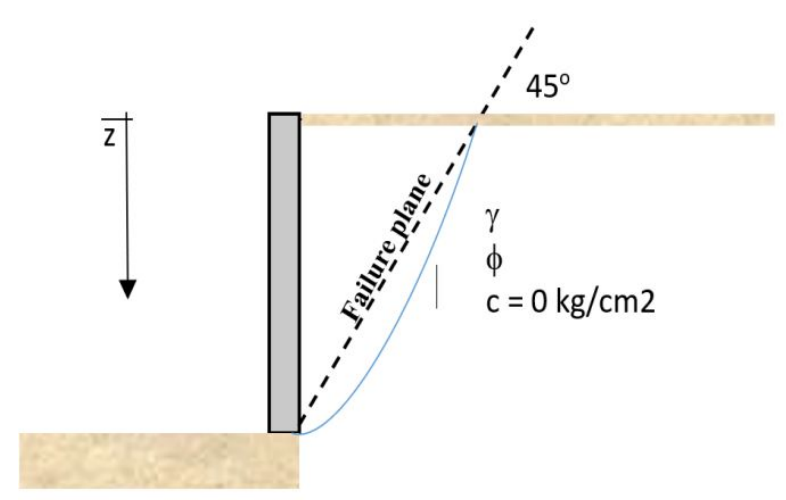

Fig. 2. Failure pattern due to static load (Rankine's theory)

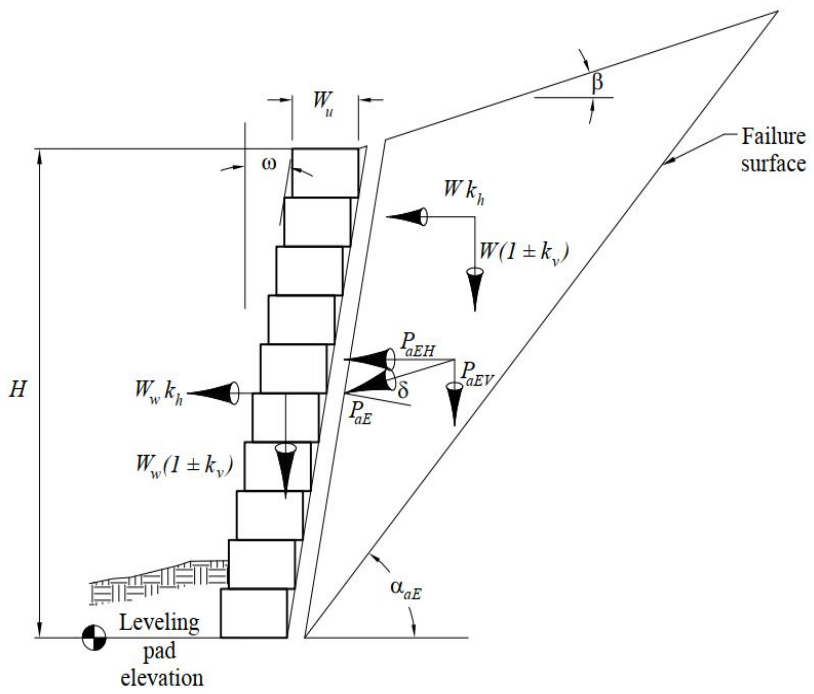

Fig. 3. NCMA, design SRW (2016)

\section{Method}

The static load is given gradually until the wall fails after the block retaining wall is arranged, as indicated in Fig. 1. During the testing process, videos are recorded, so the movement of sand grains can be seen. The next step is to determine the equation function of the failure pattern. This equation's function helps determine the wall's overall stability, as well as the backfill area and length. Analysis for overall stability using the slices method applies to flat, circular, or a combination of both.
With the method of slices, the soil block that has failed is divided into several slices. Vertical slicing is used to divide the slices. For each piece, the working forces are analyzed and calculated cumulatively. Furthermore, the safety factor of the assumed failure plane can be calculated by comparing the resisting and driving forces. Weight is determined by the soil's weight for each part is:

$$
W=\gamma(\Delta A)
$$

Next, the normal force $(\mathrm{N})$ and the tangential force $(\mathrm{T})$ act for each slice ( $\alpha$ is the slope angle assumed for each slice):

$$
\begin{aligned}
& N=W \cos \alpha \\
& T=W \sin \alpha
\end{aligned}
$$

The area of the failure (A) is calculated using the integral equation of $F(h)$ (Equation 4). $F(h)$ is a function of the equation for the height of the block retaining wall. The formula determines a slice's failure length (DL) in equation 5 . By using equation 6 , we can calculate the overall stability safety factor $(\mathrm{c}=0)$.

$$
\begin{aligned}
& \text { area of slices } A(\Delta A)=\int_{a}^{b} F(h) \\
& \Delta L=\int_{a}^{b} \sqrt{1+\left[\frac{d F(h)}{d h}\right]^{2}} d h \\
& S F_{\text {overall }}=\frac{\sum_{1}^{n}\left(c * \Delta L_{n}+N_{n} \tan \phi\right)}{\sum_{1}^{n} T_{n}}=\frac{\sum_{1}^{n}\left(N_{n} \tan \phi\right)}{\sum_{1}^{n} T_{n}}
\end{aligned}
$$

A safety factor of sliding and overturning is also investigated in this study. The force of lateral earth pressure, the weight of soil above the heel (Ws), and the concrete Wc should all be considered while analyzing the wall's stability. An active earth pressure condition will arise if the wall is pushed out due to the earth pressure behind it. According to Rankine, the value of earth pressure can be calculated as follows:

$$
\sigma_{a}=\gamma z \tan ^{2}\left(45^{\circ}-\phi / 2\right)
$$

Using the active earth pressure coefficient, $\mathrm{Ka}$, as a starting point:

$$
K_{a}=\tan ^{2}\left(45^{\circ}-\phi / 2\right)
$$

Only the weight of the soil itself contributes to the active compressive force acting behind the wall to a depth of $\mathrm{z}=$ $\mathrm{h}$ in non-cohesive soils $(\mathrm{c}=0)$.

$$
P_{a}=1 / 2 \gamma h^{2} K_{a}
$$

Equation 10 is the formula for determining the value of the safety factor of sliding. The formula for the safety factor of overturning is explained in equation 11 .

$$
\begin{gathered}
S F_{\text {sliding }}=\frac{\sum F_{R}}{\sum F_{d}}=\frac{\sum V \tan \delta+B c+P_{p}}{P_{a}}=\frac{\sum V \tan \delta}{P_{a}} \\
S F_{\text {overturning }}=\frac{\sum M_{R}}{P_{a} y}=\frac{\sum W x}{P_{a} y}
\end{gathered}
$$




\section{Result and Discussion}

Table 1 shows the data on soil properties. Because the cohesion value is equal to 0 and the sieve analysis reveals $96.096 \%$ sand, the soil type is sand. Based on observations and video recordings of laboratory experiments, the movement pattern of sand grains was obtained Fig. 4. The pattern is described in the Cartesian coordinate system Fig. 5. This pattern (failure pattern) looks like the letter $\mathrm{S}$.

Tabel 1. Sandy soil properties

\begin{tabular}{|c|c|}
\hline Type of Parameter & Value \\
\hline Unit Weight $\left(\gamma_{\mathrm{s}}\right)$ & $1,472 \mathrm{gram} / \mathrm{cm} 3$ \\
Soil Cohesion $(\mathrm{c})$ & $0 \mathrm{gram} / \mathrm{cm} 2$ \\
The angle of internal friction of & $31,699^{\circ}$ \\
soil $(\phi)$ & $96,067 \%$ \\
Sieve analysis of soil & (sand) \\
\hline
\end{tabular}

The next step is to find the equation of the mathematical function of the pattern Fig. 6. The function obtained is the equation of polynomial order 3 , which is shown in equation 12. An analysis of overall stability is performed based on the failure pattern.

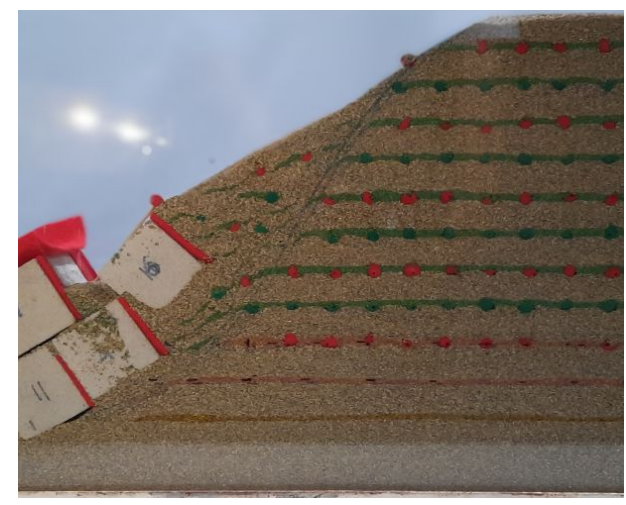

Fig. 4. NCMA, design SRW (2016)

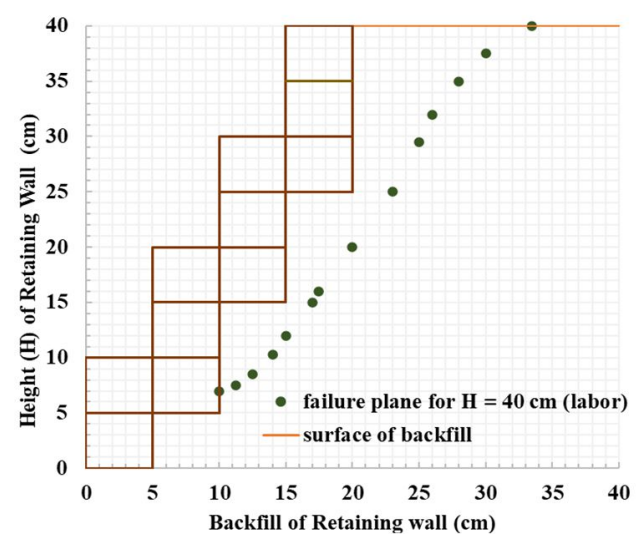

Fig. 5. Sketch of failure pattern

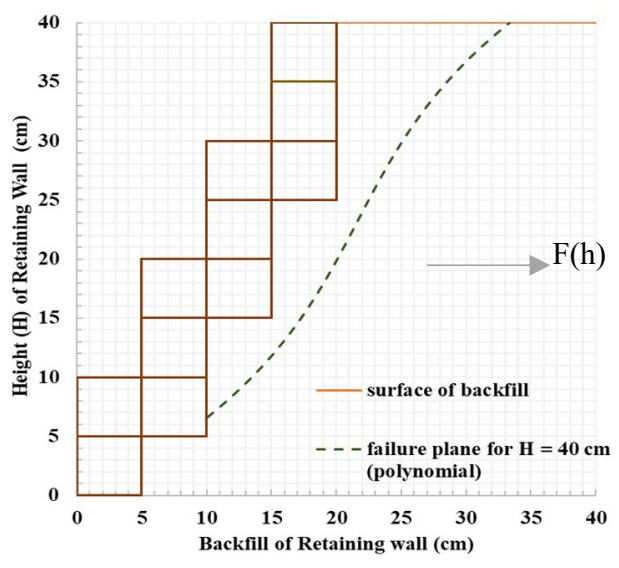

Fig. 6. The mathematical function of the failure

$F(H)=0.0008 H^{3}-0.0558 H^{2}+1.7739 H+0.5262$

\subsection{Overall Stability of Block Retaining Wall}

Based on the equation of function, the overall stability of the wall can be found. Fig. 7. shows the failure area divided into seven slices using the method of slices.

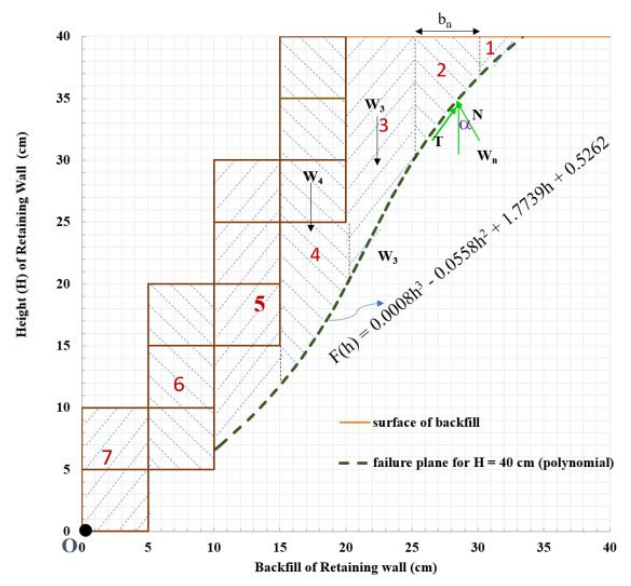

Fig. 7. Equation of failure pattern and method of slices

The area and weight of each slice are calculated using equations 1 dan 4 . Additionally, the calculation is displayed in a tabular format following:

Tabel 2. Calculation of overall stability

\begin{tabular}{|c|c|c|c|c|c|c|c|c|c|}
\hline Slice & $\begin{array}{c}\mathrm{b} \\
\mathrm{cm} \\
\end{array}$ & $\begin{array}{l}\text { Area } \\
\mathrm{cm}^{2}\end{array}$ & $\begin{array}{c}\gamma \\
\mathrm{gr} / \mathrm{cm}^{2} \\
\end{array}$ & $\begin{array}{l}\text { Weight } \\
\mathrm{gr} / \mathrm{cm}^{1}\end{array}$ & $\alpha$ & $\sin \alpha$ & $\cos \alpha$ & $\begin{array}{l}\mathrm{W} \sin \alpha \\
\mathrm{gr} / \mathrm{cm}^{1}\end{array}$ & $\begin{array}{c}\mathrm{W} \cos \alpha \\
\mathrm{gr} / \mathrm{cm}^{1}\end{array}$ \\
\hline 1 sand & 3.40 & 5.42 & 1.47 & 7.98 & 46.00 & 0.72 & 0.69 & 5.74 & 5.55 \\
\hline 2 sand & 5.00 & 32.52 & 1.47 & 47.86 & 57.00 & 0.84 & 0.54 & 40.14 & 26.07 \\
\hline 3 sand & 5.00 & 75.33 & 1.47 & 110.89 & 62.00 & 0.88 & 0.47 & 97.91 & 52.06 \\
\hline 4 sand & 5.00 & 47.47 & 1.47 & 69.88 & 52.00 & 0.79 & 0.62 & 185.09 & 144.61 \\
\hline block & 5.00 & 75.00 & 2.20 & 165.00 & & & & & \\
\hline 5 sand & 5.00 & 29.88 & 1.47 & 43.99 & 44.00 & 0.69 & 0.72 & 145.18 & 150.34 \\
\hline block & 5.00 & 75.00 & 2.20 & 165.00 & & & & & \\
\hline 6 block & 5.00 & 75.00 & 2.20 & 165.00 & 0.00 & 0.00 & 1.00 & 0.00 & 165.00 \\
\hline 7 block & 5.00 & 50.00 & 2.20 & 110.00 & 0.00 & 0.00 & 1.00 & 0.00 & 110.00 \\
\hline & & & & & & & Sum & 293.02 & 653.61 \\
\hline
\end{tabular}


The overall stability safety factor value is 1.16 , based on the preceding explanation of the slice approach (equation 6).

\subsection{Sliding Stability and Overturning Stability}

Fig. 2 depicts the forces involved in estimating sliding and overturning stability. The lateral earth pressure force $\mathrm{Pa}$, the weight (W) of the soil and concrete, and the force's distance ( $\mathrm{x}$ or $\mathrm{y}$ ) from the point $\mathrm{O}$ (toe of a wall) are all factors to consider. Table 3 summarizes the calculations used to determine the sliding stability value.

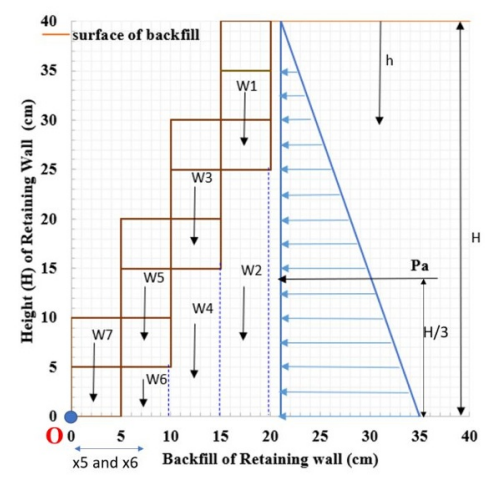

Fig.8. Forces acting on the block retaining wall

Tabel 3. Sliding stability calculation

\begin{tabular}{|c|r|r|r|r|r|}
\hline Slice & $\begin{array}{c}\text { Area } \\
\mathrm{cm}^{2}\end{array}$ & $\begin{array}{c}\gamma \\
\mathrm{gr} / \mathrm{cm}^{2}\end{array}$ & $\begin{array}{c}\mathbf{W} \\
\mathrm{gr} / \mathrm{cm}^{1}\end{array}$ & $\begin{array}{c}\text { Distance } \\
\mathrm{cm}\end{array}$ & $\begin{array}{c}\text { Moment } \\
\mathrm{gr} / \mathrm{cm}^{1}\end{array}$ \\
\hline 1 & 75 & 2.2 & 165 & 17.5 & 2887.50 \\
2 & 125 & 1.47 & 183.75 & 17.5 & 3215.63 \\
3 & 75 & 2.2 & 165 & 12.5 & 2062.50 \\
4 & 75 & 1.47 & 110.25 & 12.5 & 1378.13 \\
5 & 75 & 2.2 & 165 & 7.5 & 1237.50 \\
6 & 25 & 1.47 & 36.75 & 7.5 & 275.63 \\
7 & 75 & 2.2 & 165 & 2.5 & 412.50 \\
\hline Total & & $\mathbf{\Sigma V}=$ & 990.75 & $\mathbf{\Sigma} \mathbf{M}_{\mathbf{R}}=$ & 11469.38 \\
\hline & & $\mathbf{P a}=$ & 365.74 & 13.33 & 4875.26 \\
\hline & & $\mathbf{K a}=$ & 0.311 & & \\
\hline
\end{tabular}

The safety factor value for sliding stability is:

$$
S F_{\text {sliding }}=\frac{\sum V \tan \delta}{P_{a}}=\frac{990.75 * \tan \left(\frac{2}{3} * 31.699\right)}{365.74}=1.05<1.5
$$

The safety factor value for overturning stability is:

$$
S F_{\text {overturning }}=\frac{\sum W x}{P_{a} y}=\frac{11469.38}{4875.26}=2.35<2.5
$$

\section{Conclusion}

The failure or movement of sand grains behind the block retaining wall generates an equation of a polynomial order of three functions. Order three of the function equation can be used to calculate the overall stability value. Using the integral of the equation of the power of three functions, determine the area of failure. So that calculations using these equations will get more precise results. It is necessary to redesign the block retaining wall dimensions to obtain a safe overall, sliding, and overturning stability value.

The authors are grateful for the support of this experimental work by the Indonesian Ministry of RISTEK-BRIN, Deputy for Strengthening Research and Development. Thanks to the Department of Civil Engineering and technical support staff from the Soil Mechanics Laboratory at the Faculty of Engineering, Andalas University, for their dedication and assistance before and during the test. Thank you also to Civil Engineering Study Program, Dharma Andalas University for their support in this research.

\section{References}

1. J. A. McKelvey, Lessons Learned From Failures: The Wall of Shame, Geo-Frontiers, ASCE, 3235-3244 (2011)

2. H. Brooks, J. P. Nielsen, Basics of Retaining Wall Design, 10 th. Newport Beach California: since 1992 (2013)

3. U. C. Sari, M. N. Sholeh, I. Hermanto, The stability analysis study of conventional retaining walls variation design in vertical slope, J. Phys. Conf. Ser., 1444, 1 (2020)

4. B. Toprak, O. Sevim, I. Kalkan, Gabion Walls and Their Use, Int. J. Adv. Mech. Civ. Eng., 3, 4, 2394 2827 (2016), [Online]. Available:

http://www.iraj.in/journal/journal_file/journal_pdf/13 -271-147400929156-58.pdf.

5. M. Ramli, T. J. R. Karasu, E. T. Dawood, The stability of gabion walls for earth retaining structures, Alexandria Eng. J.,52, 4, 705-710, (2013)

6. Nimbalkar, Pain, Ahmad, Chen, Stability Assessment of Earth Retaining Structures under Static and Seismic Conditions, Infrastructures, 4, 2, 15 (2019)

7. D. I. Mazni, An alternative model of retaining walls on the sandy area to prevent landslides, E3S Web Conf., 156 (2020)

8. S. Sharma, Geo-Frontiers 2011 C ASCE 2011 2877, Geo-Frontiers 2011 C ASCE 2011 2877, 1993, 28772886, (2011) [Online]. Available:

9. A. Lim, Lesson learned from retaining wall failures: A geotechnical disaster, MATEC Web Conf., 229 (2018)

10. A. Haddad, G. Shafabakhsh, Failure of segmental retaining walls due to the insufficiency of backfill permeability, Geosynth. Civ. Environ. Eng. Geosynth. Asia 2008 Proc. 4th Asian Reg. Conf. Geosynth., no. July, 852-856 (2008)

11. NCMA, Segmental Retaining Walls Best Practices Guide, 1st ed. 13750 Sunrise Valley Drive: NCMA Publication Number: TR308, (2016) 